\title{
EL MONASTERIO DE SAN MIGUEL DE LOS REYES: NUEVOS DATOS SOBRE LA CONSTRUCCIÓN, ORNAMENTACIÓN, BIENHECHORES Y DESAMORTIZACIÓN
}

\author{
POR \\ ISABEL MATEO GÓMEZ Y AMELIA LÓPEZ-YARTO \\ Dpto. H. ${ }^{a}$ del Arte. C.E.H.
}

This article tries to complete some aspects of the construction, ornamentation, donants and desamortization of the monastery jeronimite of San Miguel de los Reyes (Valencia).

En reciente publicación sobre monumentos religiosos en Valencia, Mercedes Gómez Ferrer Lozano dedica un capítulo a la arquitectura del monasterio jerónimo de San Miguel de los Reyes, basándose no solo en la bibliografía especializada, sino también en los documentos localizados en archivos valencianos ${ }^{1}$.

Nuestra búsqueda sobre monasterios jerónimos en el A.H.N. ha dado como resultado la localización en las Actas Capitulares de información sobre la construcción del monasterio que puntualiza, completa y suma noticias sobre lo publicado en el trabajo arriba reseñado. Así mismo nos han suministrado información sobre otros aspectos artísticos, económicos, fundacionales y de mecenazgo dignos de consideración ${ }^{2}$ (Figs. 1,2 y 4 ).

Aunque vamos a deternos exclusivamente en lo aportado por las Actas Capitulares, hemos de advertir que sobre el testamento de los Duques de Calabria hemos localizado inventarios minuciosos de libros, alhajas, muebles, plata etc., también en el A.H.N., que no hemos visto recogidos en ninguna otra publicación ${ }^{3}$.

La mayoría de las noticias corresponden a la segunda fase constructiva del monasterio. Gómez-Ferrer señala la importancia de la participación de Lavall en las obras del claustro en 1573 según el proyecto inicial de Covarrubias y cómo, un año después de la muerte de éste, en 1578, se plantean las primeras dudas acerca de la traza que se seguía en el claustro. Las Actas Capitu-

\footnotetext{
1 Valencia. Arquitectura religiosa, Col. Monumentos de la Comunidad Valenciana, t. X, Valencia, 1995, pág. 190.

2 Este trabajo que hoy publicamos es un avance, junto con otro que sobre el monasterio de La Murta de Valencia se halla en prensa en la revista Ars Longa de la Universidad de Valencia, de un Proyecto de Investigación ya finalizado, sobre El Arte de los jerónimos desde los Trastamara a los Austrias.

3 A.H.N., Códices 515, 526 y 585 .
} 


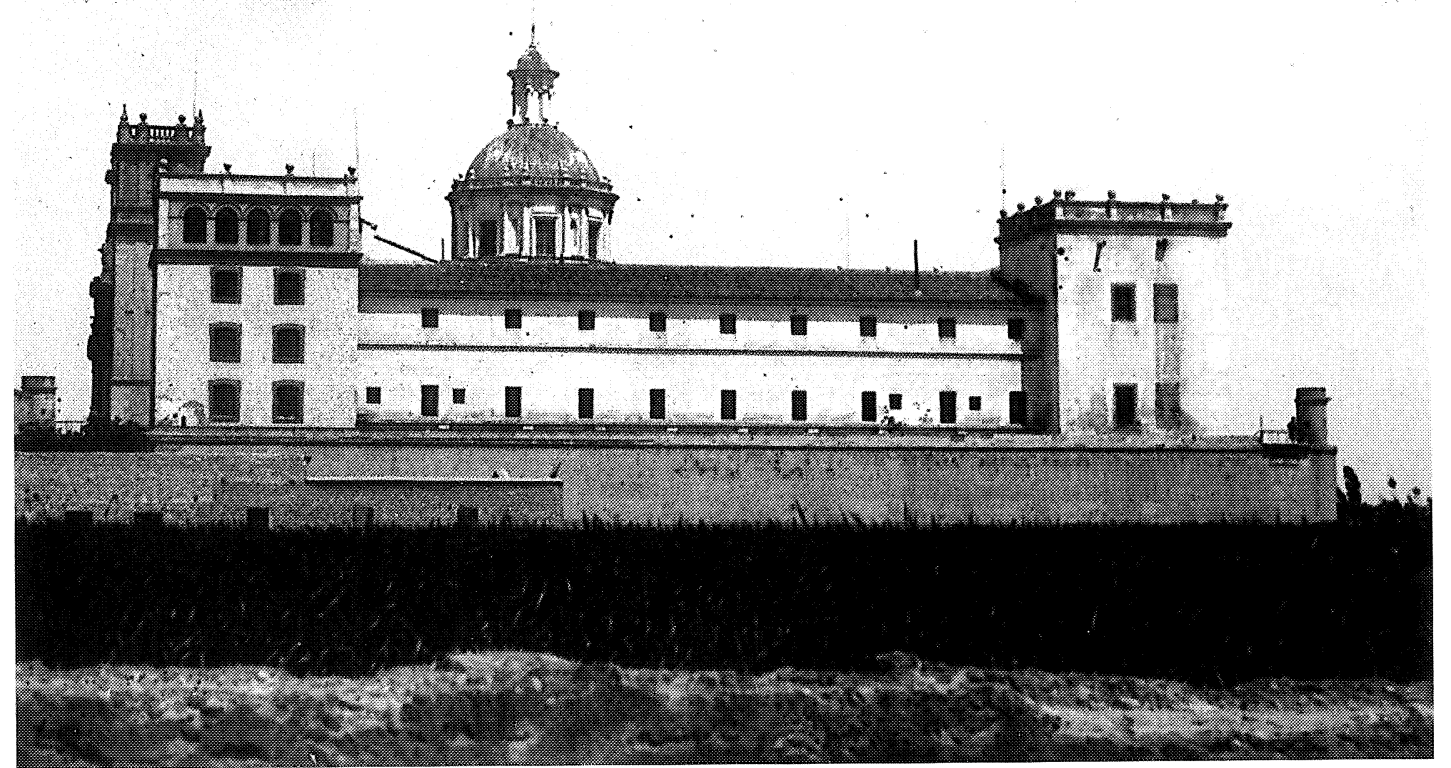

1

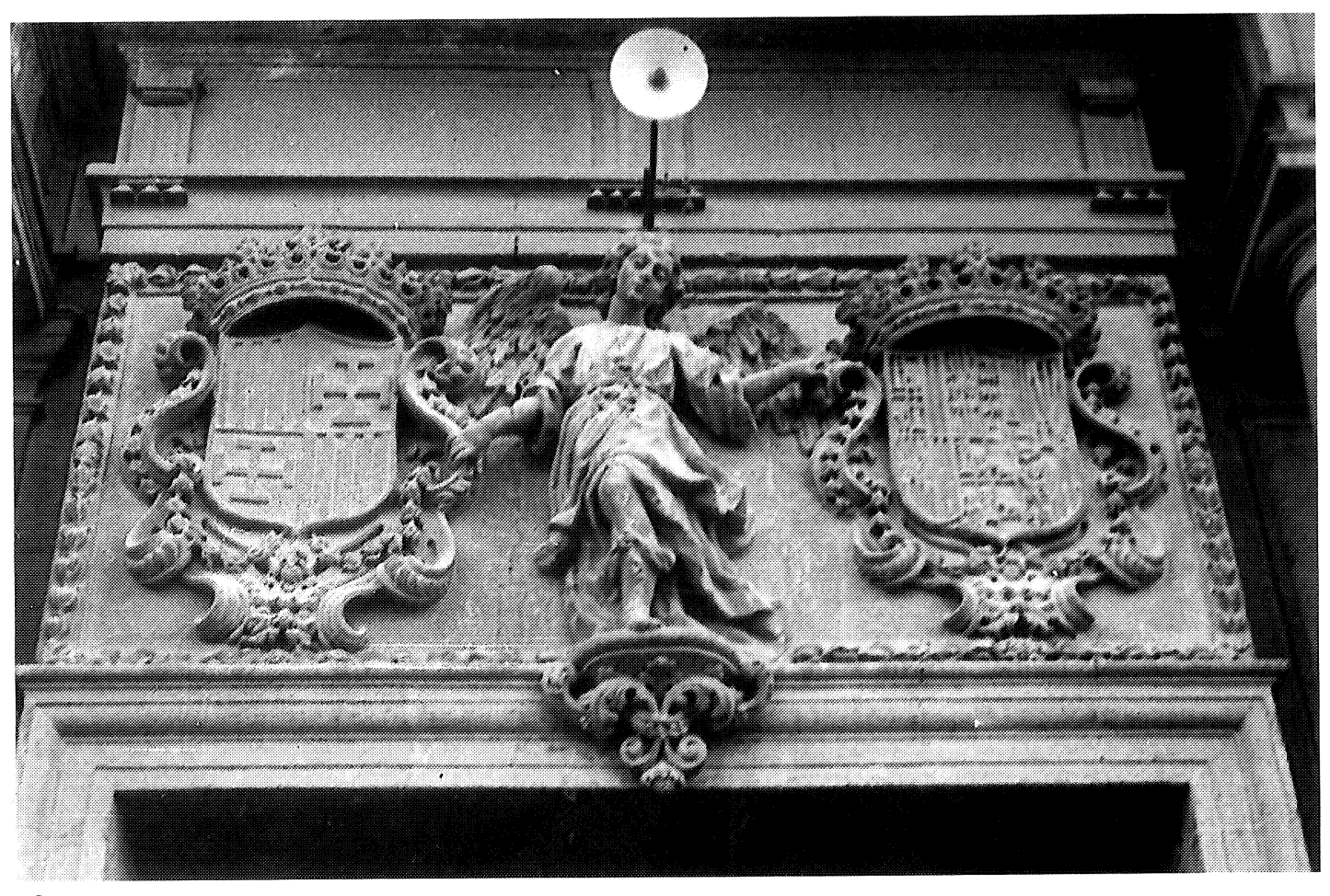

2

Figs. 1 y 2. Valencia: Monasterio de San Miguel de los Reyes: Conjunto y detalle de la fachada principal. 
lares del 18 de julio de 1578 aportan un dato importante, el cabildo propone tirar lo que ya estaba hecho y que se hiciese conforme a la traza que se había traído de El Escorial 4.

Cuando ya se decide que la obra del claustro se haga igual a la de El Escorial, en 1580, se hacen cargo de ella Juan Bautista Abril y Juan de Ambuesa. Este último presenta la traza de la escalera principal en marzo de 1580. De ese mismo mes y año hay dos noticias importantes en las Actas Capitulares, una se refiere a la escalera, sobre si la baranda debía de ser de balaustres de metal o de piedras blancas y negras, decidiéndose por esta última solución que ya estaba antes concertada con Maestre Juan de Ambuesa. La segunda noticia es sobre la conveniencia de hacer un paso al claustro nuevo y una portada en el segundo paño donde estaría la librería trazada también por Juan de Ambuesa 5. Noticia importante por lo que aporta sobre el "gusto" y "tipología» del edificio jerónimo es la noticia del 3 de agosto también de 1582 a propósito de la Capilla que está comenzada en el claustro principal en el lienzo de poniente, que dejó comenzada el Duque bajo la advocación de la Adoración de los Reyes Magos. Juan de Ambuesa, encargado de terminarla, duda de si rematarla con cimborrio o como estaban las bóvedas del claustro bajo como en el capítulo y la librería. El cabildo decide que no se haga el cimborrio porque no se usa en los claustros hacer capillas con cimborrios especialmente en los de nuestra orden.

En las Actas Capitulares de los años 1588 a $1601^{6}$, se dan noticias sobre la obra del claustro y muy especialmente sobre los retablos. A propósito de estos últimos es curioso el «impas» que se propone para su hechura. En efecto el cabildo reunido el 26 de agosto de 1588 es informado por el prior de cómo en carta del visitador, éste ordenaba que cada año se hiciese un retablo para las capillas de la iglesia, sin embargo por andar escasos de dinero a causa de la obra y otras cosas, es necesario acudir al P. General, fray Francisco de Segovia, quien moderó el mandato diciendo que bastaría con que cada tres años se hiciese un retablo. El prior había concertado con un pintor de los mejores de la ciudad y con un entallador muy bueno el hacer un retablo según la traza dada por el pintor. Se había concertado en 45 ducados y la pintura en 140 ducados, y estaría dedicado a la Concepción de Nuestra Señora, por la devoción que la reina doña Germana sintió por ella. El documento no da los nombres del pintor ni del escultor.

El 14 de octubre de 1588 el prior fray Francisco de Santa Maria propuso que, puesto que en el convento no había ningún retablo dedicado a San Jerónimo, se demorase la hechura del de la Concepción pues el de Nuestra Señora que hay al presente en la iglesia aun se puede soportar algunos años. Ferrandis Torres da una noticia del 27 de diciembre de 1589, en que se firma una apoca por la que el procurador del monasterio Juan de Villatoras pagaba a Jose Esteve 45 libras reales de Valencia como precio de un retablo de San Jerónimo hecho por éste. Nosotros hemos localizado en el Archivo de la Academia de San Fernando la documentación referente a la hechura de este retablo, pagándosele al pintor Vicente Requena durante los años 1588 y 1589 , 165 libras por pintar y dorar el retablo de San Jerónimo que estaba en una de las tribunas del piso del coro. El escultor que interviene en el retablo es, efectivamente y según dicho documento, Joseph Esteban que cobra las mencionadas 45 libras 7

En el mismo Libro de gasto de 1589-1591 se le paga a Vicente Requena por pintar y dorar el retablo de la Purísima Concepción. Como escultor se le paga al mismo Joseph Esteban. A am-

\footnotetext{
4 A.H.N., Códice 515, Actas Capitulares.

5 También en A.H.N., Libros de recibos y gastos ... de San Miguel de los Reyes, Códice 499, 1579, y Códice 498, 1590, existen pagos en el año 1585 a Juan de Ambuesa a cuenta de la librería.

6 A.H.N., Códice 515, Actas Capitulares.

7 A.A.S.F. 62-8/5. Respecto a este mismo retablo, volviendo a las citadas Actas Capitulares del A.H.N., hay una noticia en el Códice 498, del Libro de recibos desde 1590 donde se paga a Jerónimo Raquel, carpintero, por un retablo de madera para una imagen de Nuestro Padre San Jerónimo. Como obra nueva de ese año en el convento, se cita un aguamanil ejecutado por Juan Castellano, obrero de la villa.
} 


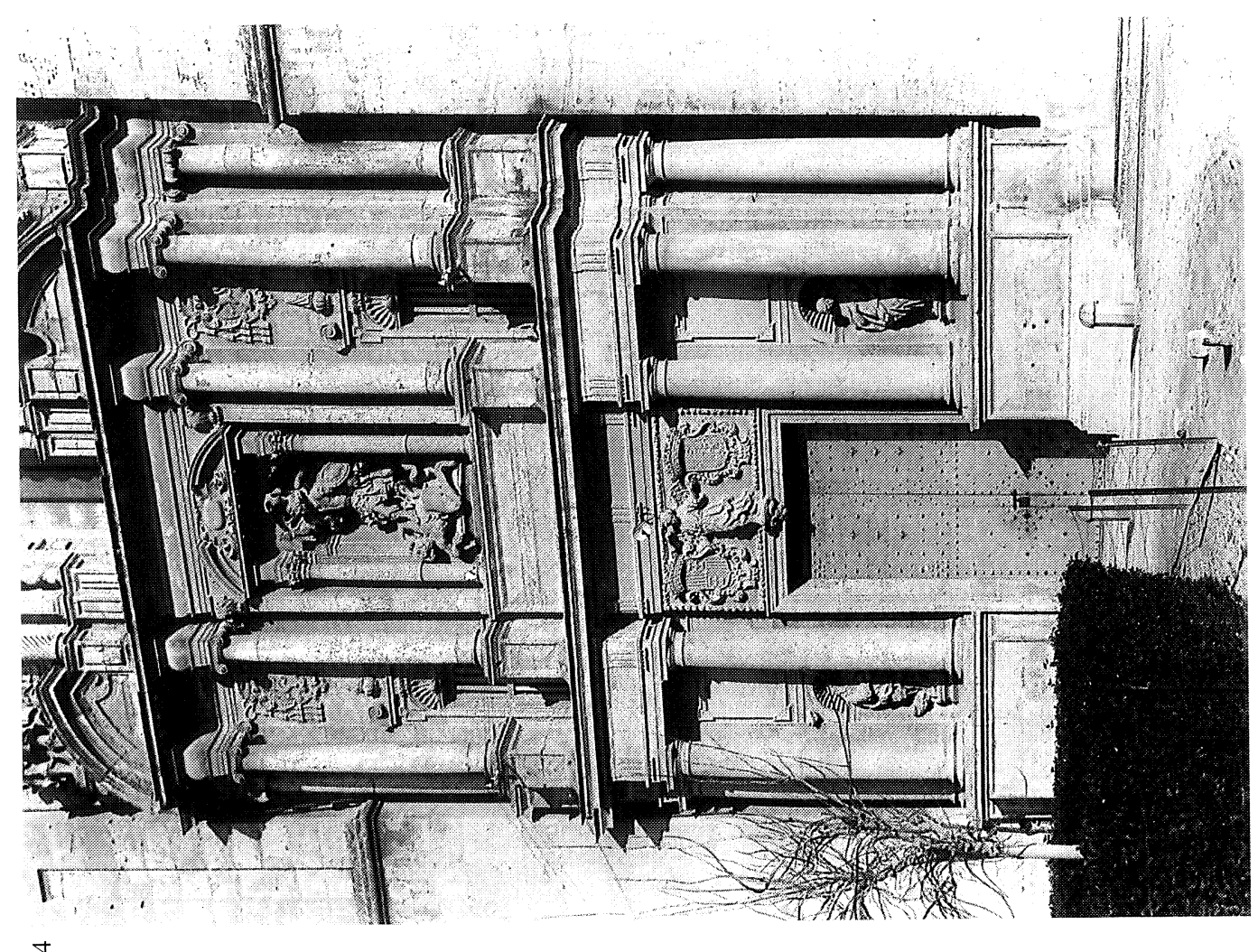

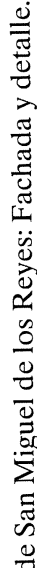

m

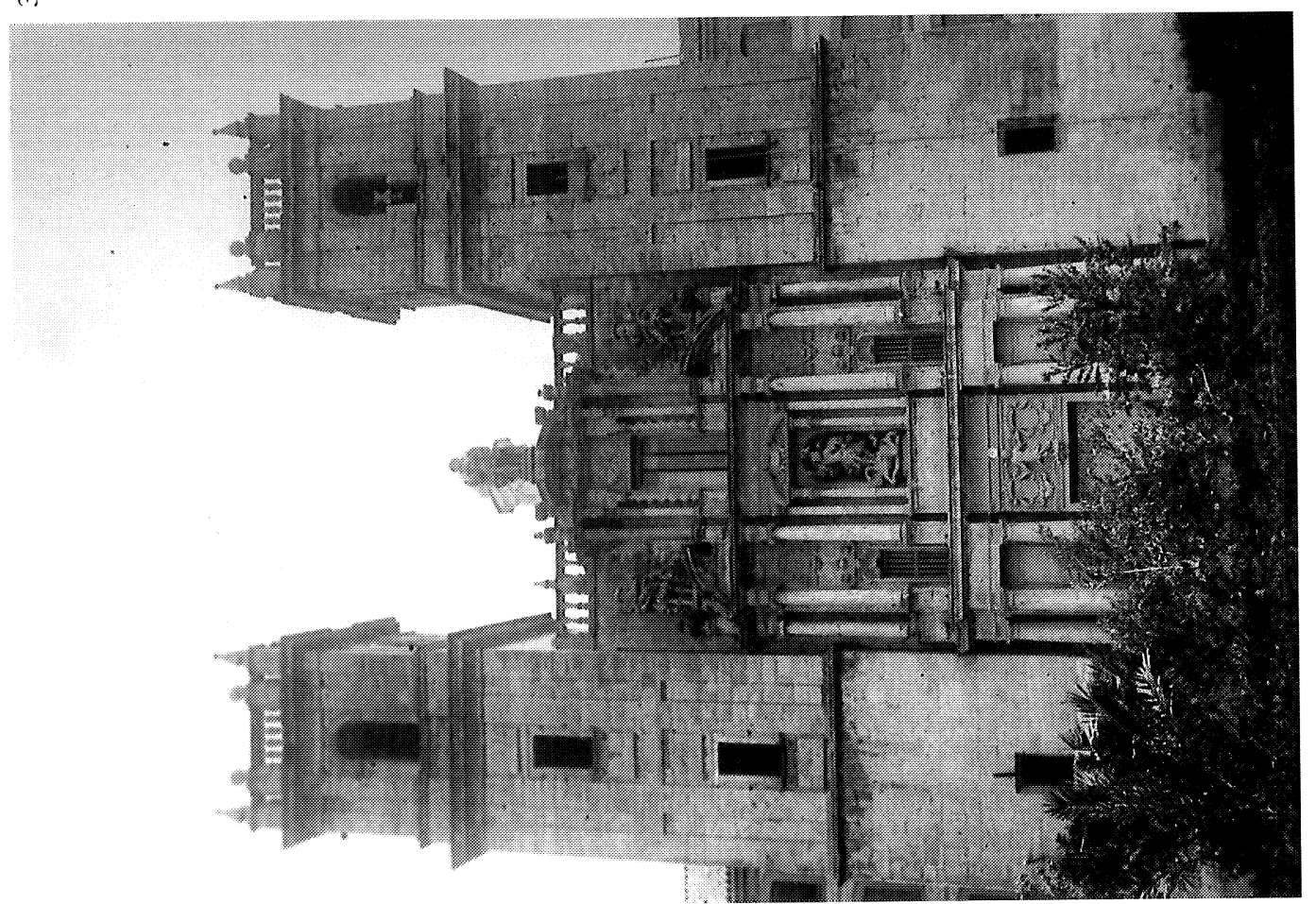


bos se les van haciendo los pagos según van avanzando en la obra. Así pues, aunque parece que momentáneamente se pensó en no ejecutar el de la Concepción por la hechura del de San Jerónimo, debió decidirse al fin hacer los dos al mismo tiempo.

Volviendo a las Actas Capitulares, el 9 de junio de 1589 el prior recuerda la estancia de fray Borrás en el monasterio para pintar un retablo de Santa Ana, pero se había ido sin pintarlo, por lo que propone que se le dé al que hace el de San Jerónimo. Este pintor no es otro que Requena, quien lo pintó por el precio de 180 libras. Los documentos al respecto, que también se encuentran en la Academia de San Fernando, datan a partir de 1594. Continúa colaborando con él el entallador Joseph Esteban ${ }^{8}$.

En este año 1594, el 11 de febrero se dice que el P. fray Cristóbal de Espinosa hacía un retablo de San Juan y San Sebastián de las limosnas de los Sermones y que se había ofrecido a pagar todo lo que tocaba a la pintura y dorado pidiendo solo la madera para las imágenes y la capilla para colocarlo. F. Benito Domenech documenta la participación de Cristóbal Lloréns en 1594 en varios trabajos para el monasterio, donde permanece hasta 1597. Estos trabajos fueron los lienzos para los retablos de San Sebastián, Santos Juanes y el de la Mgdalena 9. Los retablos de San Sebastián y Santos Juanes debieron ser costeados por fray Cristóbal de Espinosa, pues por las Actas Capitulares del 21 de julio de 1595, sabemos que debía a la comunidad 42 libras que había tomado prestadas para pagar parte de un retablo que esta haciendo y no esta acabado del Sr. San Sebastián y de los Sres. San Juan Bautista y Evangelista... solicitando que se acabase el retablo a cuenta del convento.

Volviendo a otras obras del monasterio, el 3 de junio de 1590 se propone si se debía hacer el sagrario ya que los visitadores habían ordenado que se hiciese. No obstante, el cabildo, basándose en que el Padre General había quitado a los visitadores la facultad de ordenar obras, especialmente las muy caras, sin tratar antes con la comunidad, decide no hacerlo porque hay otras cosas pendientes.

Ya en el siglo xvII, tenemos la noticia del 26 de septiembre de 1603 en que proponen hacer una librería nueva en el claustro que cae hacia el camino de Valencia. El motivo es porque ese lugar no tiene humedad. Al año siguiente se le encarga a Juan Cambra, que había sustituído -por fallecimiento- a Juan de Ambuesa, el cuarto lienzo del claustro.

En las Actas de los años 1604 a 1638, nuevas noticias de las obras ${ }^{10}$. La mayoría son referentes a Juan Cambra y muchas publicadas por Gómez-Ferrer. El 17 de mayo de 1609 se propone abrir la ventana de la "O» que está encima del altar mayor, por el mucho calor que hace en verano. Así pasaría más aire y luz a la iglesia. El 17 de julio de 1614 se hace una fuente para el claustro y una noria para la huerta. Se hace un nuevo retablo en yeso dedicado a la Concepción para la sacristía, según consta el 18 de agosto de 1619.

El 18 de diciembre de 1622, como marchan bien económicamente, se plantean la posibilidad de hacer un segundo claustro o una nueva iglesia, decidiéndose por esta última. El 19 de febrero de 1623 se hace cargo de las obras Pedro de Ambuesa que cobraría 1.500 libras una vez acabada la obra y 250 cada año para su comida. Se compromete a terminarla en cuatro años y propone la piedra de Jávea para la construcción (Fig. 6).

Importantes son también las noticias del 31 de marzo de 1627 en las que al maestro que ejecuta el retablo de San Juan del Mercado se le propone que, cuando acabe dicha obra el día de San Juan, considere que, una vez que estaba trabajando para el convento y que había demostrado

\footnotetext{
8 A.A.S.F. Leg. 62-8/5. Orellana posiblemente vio estos documentos referentes a Requena y los retablos que hizo en San Miguel de los Reyes.

9 F. Benito: Los Ribalta y la pintura valenciana de su tiempo, Valencia, 1987.

10 A.H.N., Códice 507.
} 
que era un buen maestro concertara el retablo de la nueva iglesia y los sepulcros de los fundadores. Como el gasto es grande deciden tomar a censo cada año 6.000 libras durante dos años, dando al maestro 1.000 libras anuales de dichos censos, una vez acabada la obra. El cabildo, reunido el 27 de junio de 1627, decide que el altar sea de piedra. El 5 de julio del mismo año se trata con Juan Miguel [Orliens] el concierto de los sepulcros, ya que pedía 5.000 libras, advirtiendo que otros maestros castellanos a los que se había consultado no pedian menos de 6.000 ducados.

El 16 de diciembre de 1628, Pedro de Ambuesa informa que en cada luneta de la cornisa iría bien abrir una ventana o puerta, no solo para dar paso a aposentos, sino para remediar más facilmente en caso de que haya alguna gotera y para «otros beneficios». Si por donde están los sepulcros no se puede abrir, se abriría por el testero.

Las noticias del 29 de abril de 1629 son a propósito de los reyes que se han de poner en la portada de la iglesia. Cuando se corten y desbasten en la cantera debe estar presente algún maestro hábil en esculpir proponiendo a maestre Andrea Ferrandis [pone Esteve entre renglones] ${ }^{11}$ (Fig. 3).

El 19 de enero de 1631 el maestro Pedro de Ambuesa propone hacer en el cimborrio de la iglesia unas ménsulas en las pilastras que se van a hacer entre las ventanas y unas columnas de medias cañas con un atalajado volante por la parte exterior. El 18 de febrero de 1631 se pone debajo del coro las rejas de la iglesia.

Una nota curiosa referente a los sepulcros de los fundadores aparece el 24 de junio de 1632. En esta fecha se estudia la oportunidad de seguir adelante con la obra, dando a Juan Miguel 700 libras cada año supuesto que se busca traza para que el convento no se cargue cosa por los entierros. Todavía en 1636 se hacen obras en el tejado del claustro junto a la iglesia, haciendo un aposento abovedado para evitar el agua.

Las Actas Capitulares de 1639 a 1694, aunque están dedicadas a la hechura de objetos de plata etc., traen todavía alguna noticia sobre las obras ${ }^{12}$. El 14 de marzo de 1642 se propone quitar un arco del coro porque afeaba la obra; el 18 de ese mismo mes y año se propone hacer la linterna en el cimborrio para no cargarlo; el 23 de agosto el prior se queja de que Pedro de Ambuesa abandona frecuentemente la obra ocasionando, sin embargo, gastos de criados, por lo que podría darse la obra al maestro Martín o a otro maestro, ya que había engañado en el concierto del coro, resultando feo y más caro. El 13 de junio de 1649, referente al retablo para la última capilla de la iglesia, el prior dice que no se podía acabar con el precio ajustado en el concierto con maese Luys por haber muerto; Andrés Antich se obliga a acabarlo si el convento le daba 50 reales. El 8 de septiembre de 1653 emprenden la hechura de la reja de la escalera que baja al presbiterio. La hace Martín de Olinda, era de balaustres de hierro y la escalera bajaba del claustro nuevo al presbiterio y sacristía. El 28 de enero de 1668 proponen restaurar el lienzo del claustro de poniente que amenaza ruina. Como no hay dinero se piensa que podría llevarlo a cabo un albañil. Finalmente el 18 de febrero de 1685 se decide tirar lo viejo de la portería, por ser peligroso, haciendo dos arcos. Esta solución la da el albañil Francisco Martínez.

Las Actas Capitulares que abarcan desde 1694 a 1735 aportan noticias de muebles y sobre todo del altar mayor ${ }^{13}$. El primer documento es del 11 de julio de 1732 y en él el prior propone que sea hecho de piedra negra y blanca y jaspe, por los legos que hay en la casa -como oficiales- y el maestro Joseph Montana. El Catálogo Monumental de 1983 cita -según documento capitular localizado por nosotras- al maestro José Caballer, muy diestro en mármoles de diversos colores, como director de la obra que terminó en 1740 (Fig. 6).

11 Tomás Lleonart Esteve trabaja con Pedro Ambuesa en 1627 en la iglesia parroquial de Lliria. Ver nota 1, pag. 200 .

12 A.H.N., Códice 508.

13 A.H.N., Códice 509. 

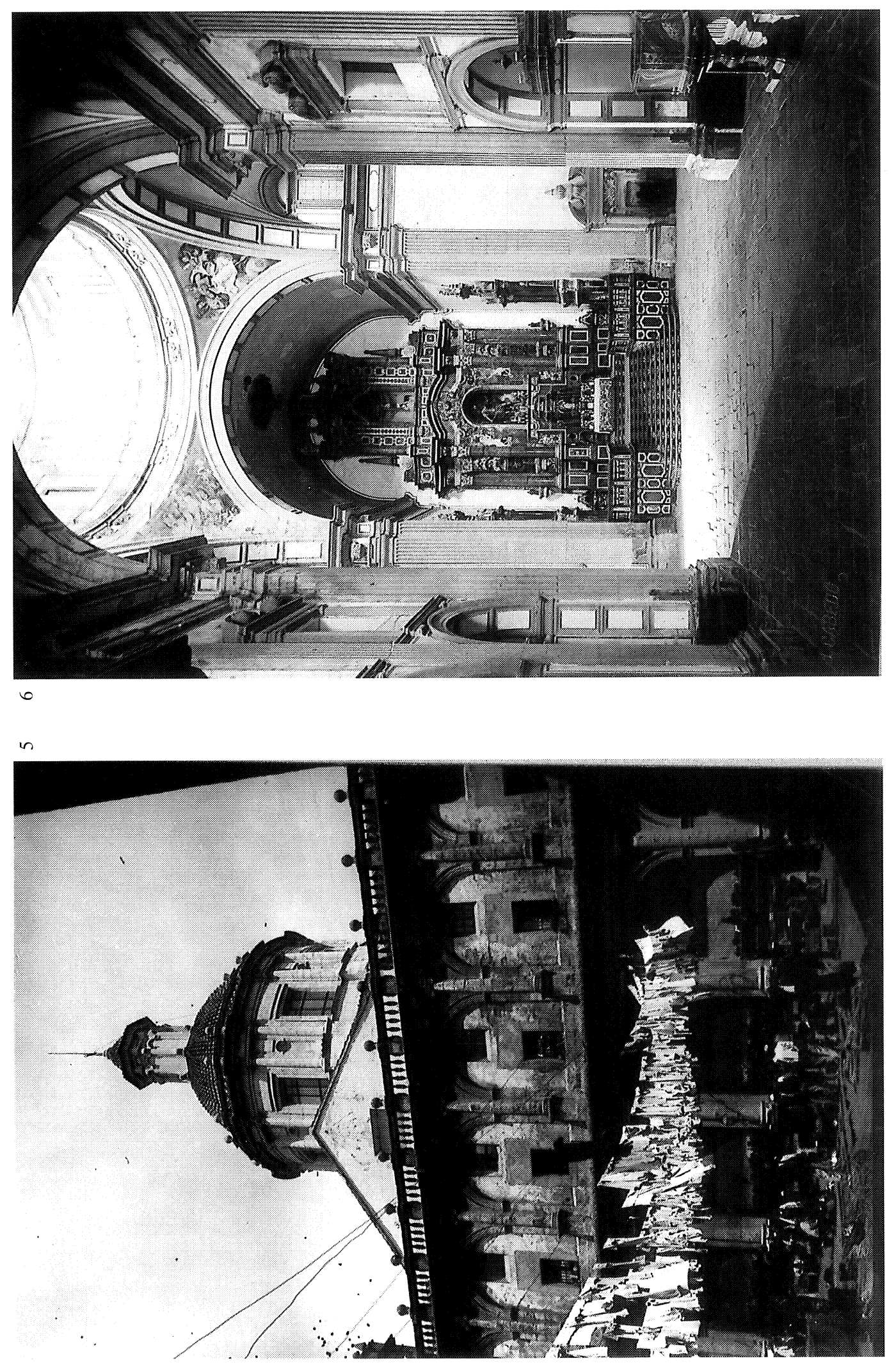

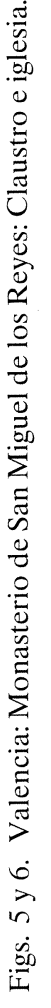


Las Actas de los años 1735 a 1764 se refieren a la escultura del retablo y otras obras que siguen haciéndose en el monasterio ${ }^{14}$. La intervención de Raimundo Capuz es conocida por los historiadores, pero es curioso el aspecto económico al tratar el precio a cobrar por la imagen de San Miguel Arcángel. A la comunidad, reunida el 17 de diciembre de 1737, le parece muy poco las 200 libras que ha pedido, porque por su calidad consideran que vale más. También les sorprende el que a Capuz no le importe no cobrarlas de golpe, sino poco a poco.

El 23 de marzo de 1753 se solucionan varias cosas en la reunión del cabildo. Se hacen nuevas celdas, se continúa la obra del retablo de la capilla de San Jerónimo, se hace la acequia del huerto y se continúa la obra del panteón de los fundadores.

El 24 de septiembre de 1760 se propone limpiar y componer la capilla de San Juan, haciendo un retablo de madera para colocar la imagen de Santa Bárbara. Pero es en la reunión del cabildo del 13 de noviembre de 1762 cuando de nuevo se propone el comienzo de una obra importante, el claustro que faltaba, por hallarse el claustrillo viejo en mal estado. Se plantea hacerlo siempre que el convento no se empeñe económicamente y que se hiciera conforme a un diseño que previamente fuera aprobado por dos maestros de los más inteligentes y hábiles de esta ciudad. Durante los años 1768 y 1769 hay noticias sobre la construcción del claustro nuevo, que no se terminó ${ }^{15}$.

Como los religiosos pasan frío en el claustro de arriba por estar abierto, el 19 de enero de 1778 deciden cerrar los claros con tabiques de ladrillo, dejando en cada lienzo cuatro ventanas sobre el antepecho, de seis palmos de anchas y diez de altas, y, bajo los arcos, en cada blanco, una ventana de siete palmos en cuadro en estas piedras de luz(Fig. 5).

Las Actas Capitulares desde el año 1786 se refieren a las obras de decoración de la iglesia y decoraciones efímeras, pero el 27 de septiembre de 1786 hay una noticia referente a obras. Se determina hacer cuatro frontales de piedra y, para para ello, era preciso comprar mármol o deshacer la fuente del claustro que se hizo en 1614, sustituyéndola por un pozo decente que fuese correspondiente a la hermosura de la obra del claustro ${ }^{16}$.

En las Actas Capitulares de los años 1796 a 1807, además de recogerse el litigio sobre la campana que donó el Duque de Calabria prosiguen las obras de reforma del monasterio ${ }^{17}$. El 4 de mayo de 1797, a la vista de lo inconveniente que resultaba el tener la hospedería dentro de los claustros, deciden sacarla fuera de la clausura y ponerla encima del cuartito de las visitas, según el proyecto que presentó fray Francisco de Santa Bárbara. Se entraría por el ramo de la derecha de la escalera saliendo del coro, y el plan fue aprobado por los directores del muelle que acababan de llegar de Madrid, quienes afirmaron que, lejos de afear, hermosearía la escalera. Se supone que se trataba del puerto de Valencia y que por ello se les considera expertos. Referente a esta obra hay nueva noticia el 9 de abril de 1801 en la que se decide que el sitio más conveniente para la hospedería es la Bodega vieja.

$\mathrm{Al}$ año siguiente, el 4 de octubre, con motivo de la venida a Valencia del Rey, se dice que el arquitecto Juan Lacorte había proyectado abrir dos puertas colaterales a la portada antigua levantando la pared que debía servir a dichas puertas a una distancia proporcionada, adornándola al mismo tiempo con un Orden de Arquitectura sencillo y majestuoso. De esta manera se conseguía que desde el Camino Real, se apreciaran mejor varios lugares del monasterio, como el patio interior y la gran fachada de la iglesia. El 27 de diciembre de 1802 deciden que las estatuas de los fundadores y los cuatro leones, que habían servido para el adorno del Camino Real, como estaban muy

14 A.H.N., Códice 510.
15 A.H.N., Códice 511.
16 A.H.N., Códice 512.
17 A.H.N., Códice 513. 
bien ejecutados, no debían deshacerse, sino colocarse en los ángulos de la Capilla del Santo Cristo, la de los fundadores, en el claustro, y los leones sobre un pedestal a la bajada de la escalera principal.

Todavía en las Actas Capitulares desde 1807 hay noticias de obras, aunque menores, pero interesantes porque se refieren a la reintegración de los frailes después de la toma francesa ${ }^{18}$. El 9 de julio de 1814 se da cuenta de las diligencias practicadas para el restablecimiento del monasterio, posesión y reintegro de todos sus bienes y propiedades con Peregrín Bayarri y Josef Ricós, arrendadores del huerto desde la toma por los franceses, para establecer las condiciones de las cosechas venideras. Se resolvió también el derribo de las oficinas y obras contiguas al claustro viejo y también del mismo por amenazar ruina. Ese mismo año y mes se piensa dónde se hacía la portería nueva, informando el arquitecto que era conveniente hacerla por la capilla del Santo Cristo, por ser la más proporcionada, estar en mejor estado y por lo tanto el coste sería menor.

Todas estas obras supusieron un serio coste al monasterio aunque buena parte de ellas se hicieran con el legado del Duque de Calabria. Desde el año 1550 ya encontramos quejas de los jerónimos al Duque a propósito de que no cumple todo lo convenido. El 11 de marzo de ese año el Duque se compromete a proseguir y acabar la obra del monasterio haya o no haya hacienda de la reina, en cuyo caso se suplirá lo que falte para llevar a cabo la dicha obra, conviene a saber el claustro nuevo comenzado y la iglesia según la traza de Covarrubias, excepto la Capilla de los Reyes que se hace en el dicho claustro nuevo y la sacristía, todo queda al parecer del padre prior de la Vitoria y el de Vidaña, prior de San Miguel, maestro de la obra 19.

Hay otras noticias que nos hablan de la penuria económica por la que pasa el monasterio. Así el 14 de febrero de 1554 se cubre la deuda a los criados vendiendo a la marquesa de Eliche la cruz de los diamantes en 330 coronas y el retablo de oro de Santa Catherina. El día 16 envían a fray Antonio Juan - profeso de la Murta de Barcelona- para que cobre en Sicilia y Nápoles cantidades que debían al convento de San Miguel, por herencia del Duque, de las infantas y de la Reina Germana. Con ellas se pretendía hacer frente también a las obras y otras necesidades del convento. Al mes siguiente, el día 26, se vuelve a hacer una venta para pagar a los criados. Esta vez se trata del diamante puncta que estaba en la espinella. Interviene en la venta -que se hace en 1.400 ducados- el platero Tremcher [?] asalariado del convento para este tipo de ventas ${ }^{20}$.

Pero San Miguel de los Reyes, además de vender para remediar sus agobios económicos, tiene que recurrir -eso sí por orden superior- a sufragar las necesidades de otros conventos. El 13 de noviembre de 1554 el General de la Orden les escribe pidiéndoles que vendan algunas joyas de las que dio el Duque de Calabria, en especial las piedras preciosas y balaxes, para remediar las necesidades de Lupiana. Deciden darle además las joyas que en ese momento había en la casa y la espinella tortuga, así como otros tres balaxes y el jarro y vinajeras de oro y el cetro o maza de calcedonia ${ }^{21}$.

Las ventas de joyas no se hacen solo en España, el 12 de enero de 1556 piensan que fray Antonio de Madrigal, prior de Espeja, y otro fraile de Guadalupe, que van a Roma por negocios de la Orden, podían llevar varias joyas para venderlas en Italia. Entre ellas se citan espinellas, el balaxe que se dice de Daranga y los dos balaxes llamados aracadas o çarçillos. El miedo a los peligros del mar y a los ladrones les hace desistir pues, además la espinella tine un diamante punta muy rico. En ese mismo año los criados siguen reclamando y se les paga con objetos porque no

\footnotetext{
18 A.H.N., Códice 514

19 A.H.N., Actas Capitulares, Códice 515, 11 de marzo de 1550

20 Loc. cit., nota 19

21 Loc. cit., nota 19.
} 
hay efectivo. En algún caso como el de Germana de Ares, criada de las infantas, se trata de una deuda del Duque para su casamiento ${ }^{22}$.

El 5 de marzo de 1559, en una acción de toma y daca acuerdan dar a las beatas de San Román de Medinaceli 1.000 escudos para que la Duquesa de Medinaceli procurase con más diligencia cobrar los 7.429 escudos que debe Sicilia al convento. De nuevo se vuelve a pedir el pago de esta cantidad a la regia corte de Sicilia el 10 de agosto de 1561 y, con esta misma fecha al rey de Francia que también tiene deudas con el convento, entre las heredadas del Duque ${ }^{23}$.

Continúa la venta de joyas pidiendo permiso al general el 17 de agosto de 1564. El 11 de enero de 1569 venden las joyas que tiene la casa al Conde de Benavente por 10.000 ducados. De cómo siguen haciendo frente económicamente a las diversas empresas que tienen, es buen testimonio otro documento del mismo día, en el que el convento, considerando los muchos pleitos que tiene, los grandes gastos, las muchas inquietudes y desasosiegos... y otras muchas cosas piensa poner en manos del Rey [Felipe II], los lugares, bienes, hacienda, acciones y pretensiones que esta casa tiene y también la herencia de la Reina y del Duque hasta quedarnos sin cosa alguna y hacerle llana donación de todo y que él nos amparase y tuviese por hijos y que él nos obrase casa y diese de comer para cincuenta frailes. El Rey no debió aceptar porque a lo largo de los años se ve que la comunidad sigue haciendo frente a los gastos del convento. El 20 de marzo de ese mismo año continuan vendiendo cosas, en este caso blandones de plata, vinajeras, mitra y cetro, tapicería, dosel y paños porque no sirven para casi nada 24 .

En el año 1578 pactan con el platero Alonso Ferriz, dándole 40 libras para acabar el pleito que tenían ( 28 de febrero) y, el 19 de marzo, en el que aún siguen debiendo dinero el Rey de Francia, el Duque de Florencia, Nápoles y Sicilia, entra en escena un caballero italiano, Juan de Fondrato, como cobrador de morosos, ofreciéndose a cobrar las deudas, a cambio de recibir la cuarta parte de lo conseguido ${ }^{25}$.

Ya no hay ninguna noticia de ventas hasta el 4 de octubre de 1590 en que se venden ropas de sacristía, sedas y brocados. No parece que en este caso sea para cubrir necesidades económicas, pues el 11 de junio de ese año se hacen casullas blancas para fiestas y frontales morados para cuaresma. Lo mismo ocurre en 1597, 1 de mayo, en el que se propone cambiar misales viejos de pergamino por otros más útiles, aunque se pagara algo más; y que Eva [?] platero de la casa hiciese un viril para la cajita de cristal del Smo. Sacramento con ángeles, cruz y remate. El 22 de agosto conviene en que se haga un monumento nuevo de manos de algún pintor de lienzo. El 24 de diciembre se decide comprar la Biblioteca [LOH]umiliarum Sanctorum, en cinco tomos y la Biblia de Batablo en dos volúmenes por 90 reales castellanos. $\mathrm{Al}$ año siguiente se hace un palio para el Santísimo y el 5 de marzo de 1600 varias piezas para la sacristía y el altar mayor entre las que destacaríamos la lámpara de plata ${ }^{26}$.

Entre los años 1639 y 1694 se continúa engalanando al monasterio con piezas suntuarias. No parece que haya problemas económicos ${ }^{27}$. El 10 de julio de 1644 se propone comprar una custodia de bronce dorada y alguna parte de plata con mucha pedrería y singular hechura que había traído desde Madrid a Valencia para venderla el platero Gerónimo del Vado, que la daba por el precio de 400 reales y con una forma de pago muy cómoda, ya que el platero aceptaba los blandones de plata de la sacristía que estaban en mal estado y repararlos costaba mucho. Se compra la custodia y, además de los blandones, se da el portapaz viejo de plata sobredorada de la sa-

\footnotetext{
22 Loc. cit., nota 12.

23 Loc. cit., nota 19.

24 Loc. cit., nota 19.

25 A.H.N., Códice 506.

26 Loc cit., nota 25.

27 A.H.N., Códice 508.
} 
cristía y las puertecillas y pie del relicario esmaltado por estar viejo y desalustrado. De esta última pieza, pues, se reservan la plancha esmaltada del centro para hacer otro portapaz.

El 13 de noviembre de 1644 proponen dorar con oro bruñido o con oro mate los bultos de los fundadores, sirviendo de ejemplo el Angel de la Guarda de la sacristía, en mate, y una Virgen, estofada. Deciden que se haga en mate por ser más parecido al bronce. El 22 de enero de 1652 se hace un órgano grande de acuerdo con la magnificencia de la iglesia. Un maestro pidió 360 reales y se hizo vendiendo plata para pagarlo.

El 12 de junio de 1656 regalan un retablito a la iglesia de Benimanet y el 20 de abril de 1659 se mejora el adorno del Lignum Crucis con alguna plata de la sacristía que ya no servía. El 21 de mayo de 1679 se cambian libros duplicados de la librería por otros nuevos.

Lo mismo ocurre durante los años 1694-1735 28. Del 8 de febrero de 1695 hay una noticia sobre los paños de Ras de la Historia de Alejandro y Nabucodonosor que se estaban pudriendo y no se podían restaurar ni vender, por lo que proponen quemarlos sacando de ellos la plata para aprovecharla en otra cosa. El 19 de mayo de 1704, se decide hacer un armario para las reliquias que había regalado el Duque de Medinaceli. Se habían presentado dos trazas eligiendo el 6 de julio de 1704 a Antonio Aparicio y a Pedro Cebrián para llevar a cabo una de ellas, ajustándolo en 160 libras. Al año siguiente, el 27 de febrero se le paga un extra a Antonio Aparicio, carpintero, por haber concluído el armario considerando que había hecho más de lo que se solicitaba en la traza y había puesto mucha madera y hierro, lo que les hace pensar que ha perdido dinero. El 28 de diciembre de 1752, nuevas obras de platería. Piensan hacer dos candeleros de plata fundiendo los dos antiguos donados por el Duque de Calabria. Los llevan al platero Almela, pero les desaconseja la fundición de los antiguos porque perderían todo el oro que tenian en las cartelas en contacto con el fuego, siendo necesario volverlos a dorar. Deciden componerlos lo mejor posible para no deshacer las alhajas de la fundación del monasterio.

En las Actas Capitulares desde el año 1765 continúan los adornos para la iglesia, sacristía y otras obras ${ }^{29}$. El 23 de abril de 1767 el monasterio presta plata y lámparas al gremio de plateros para el altar de la procesión y fiesta del centenario de la Virgen de los Desamparados. El 23 de marzo de 1768 deciden que todos los diezmos que se cobren, se empleen en adornos y menesteres de la iglesia y sacristía, porque no era justo que todo se gastase en la obra del claustro. El 20 de agosto de 1772 se encarga al maestro campanero Andrés Borrás, de Valencia, hacer una campana nueva con la misma voz que tenía antes y el mismo tamaño. Tardaría en hacerla seis años.

Desde el año 1786 se suman a las obras de decoración de la iglesia, otras decoraciones efímeras para festividades ${ }^{30}$. Al mismo tiempo el convento presta plata y tapices para festejos oficiales ajenos a él. Para la beatificación de fray Nicolás Factor y fray Gaspar Bono se prestan al arzobispado y al convento mínimo de San Sebastián, tapices, santos y platos de plata para adornar el altar, así como retratos de los familiares de su fundador. También se prestan tapices al arzobispado y a la universidad para la fiesta de exaltación al trono de Carlos IV. La riqueza en plata del convento abrió la sed de hurto de las capillas de su iglesia. Por ello el 30 de abril de 1791 deciden que las capillas se cierren con rejas de madera, pues no hay dinero para hacerlas de bronce, pero pintadas de manera que se correspondan con la hermosura de la iglesia. Siguen prodigando su asistencia a otros monasterios jerónimos decidiendo el 25 de octubre de 1791 enviar una limosna a Santa Ana de Tendilla, por los apuros que pasaban.

\footnotetext{
28 A.H.N., Códice 509.

29 A.H.N., Códice 511.

30 A.H.N., Códice 512.
} 
Desde el año 1793 comienzan las aportaciones del monasterio al Rey en su lucha contra los franceses. El 21 de marzo de 1803, José Carlos Quinzá, maestro platero de la ciudad suplica le nombren platero del convento, ya que su padre también lo había sido. Del 1 de diciembre de ese mismo año hay una noticia que nos da idea de la riqueza bibliográfica de la $l i$ brería del monasterio. El secretario del arzobispo de Valencia solicita el préstamo de la obra de Plinio manuscrita para sacar una copia y remitirla a Roma -lo que parece indicar que allí no existía- al cardenal Antonio Despuig y Dametro. Conceden el préstamo con la condición de que el secretario del obispo don Vicente Ferrer deje un recibo firmado de su propia mano, obligándose en él a devolverlo en el mismo estado en que se le entrega, y abonar todos los perjuicios que pudieran resultar.

Las Actas Capitulares de 1807 se refieren a ventas de alhajas y otras cosas para asistir al Rey en los gastos de la guerra, y el 8 de febrero de 1811 se decide que, como los franceses han entrado en Tortosa, el archivo y la biblioteca del fundador se metan en cajones para llevarlos a lugar seguro ${ }^{31}$.

Respecto a los benefactores del convento, desde la herencia de los Duques no vuelven a recibir otra hasta el siglo xvIII, concretamente el 28 de diciembre de 1708 en que el cabildo se pregunta qué hacer con las alhajas y bienes dejados en el testamento de doña Ana del Pozo. Deciden que la mitad sea para la comunidad y la otra para misas ${ }^{32}$.

A propósito de los enterramientos y fundación de capillas hay noticias desde el siglo XVI. La primera con fecha 27 de julio de 1578 se refiere a la concesión a Cosme Ximeno, labrador, de un enterramiento para él y su familia delante de la capilla de San Bernardo ${ }^{33}$. En el Libro de los recibos y gastos de San Miguel de los Reyes de $1 .^{\circ}$ de enero de 1579 y 1590 se paga a Pedro Moliner por tres capillas del claustro ${ }^{34}$. No se especifica ningún dato más, por lo que hay que suponer que son encargo de la comunidad. El 30 de diciembre de 1595 Domingo Ximeno funda la capilla del Santo Cristo para su sepultura, la de su mujer e hijos. Se indican las medidas de la sepultura y que la capilla llevaría reja y pila de agua bendita ${ }^{35}$. El primero de octubre de 1614 proponen que se ponga en la tabla de los bienhechores, inmediatamente detrás de los fundadores, a Diego de Oñate, capellán del Rey y de la Capilla de los Reyes Nuevos de Toledo, por haber intervenido en el cobro de las 71.000 libras que desde hacía 68 años debían al convento de un depósito que Carlos V tomó de él. También se le ofrece para su entierro que pueda escoger la capilla que más le guste de las que están fuera de la reja de la iglesia ${ }^{36}$. Dos años más tarde, el 29 de julio de 1616 deciden que, como el convento está muy obligado con Adrián Bayarte y, además, va a continuar recibiendo beneficios de él, se le conceda una capilla en la iglesia para su entierro, ofreciéndose Bayarte a dotarla. El 2 de octubre de ese mismo año, Bayarte se queja de que aún no le han asignado capilla y que su padre está muy enfermo. Al día siguiente le asignan la que ellos consideran más hermosa y cercana al altar mayor, dándole primero la de Santa Ana y, tras una breve meditación, la de la Magdalena -fuera de la reja- depositando ese mismo día Adrián Bayarte el cuerpo de su padre ${ }^{37}$. El 9 de agosto de 1655 se le concede al maestro Martín de Olinda fundar una memoria en el convento para cuando muriese ${ }^{38}$. El 18 de diciembre de

\footnotetext{
31 A.H.N., Códice 514.

2 A.H.N., Códice 509.

33 A.H.N., Códice 515.

34 A.H.N., Códices 499 y 498.

35 A.H.N., Códice 506.

36 A.H.N., Códice 507.

37 A.H.N., Códice 507.

38 A.H.N., Códice 508.
} 
1668 es fray Guillén Catalá el que hermosea con 100 libras suyas la capilla de Nuestra Señora de la Leche haciendo una lámpara para ella ${ }^{39}$.

La dispersión de los fondos del monasterio y la ruina de la edificación sobrevino con la Desamortización. El Archivo de la Academia de San Fernando ${ }^{40}$ aporta documentación sobre ello. Así, en el Leg. 53-3/2, sin fecha, hay un informe de la Comisión de Monumentos diciendo que deben hacerse los mayores esfuerzos para adquirir el monasterio de San Miguel de los Reyes, ya que el comprador está en buena disposición para cederlo al Estado, pudiendo reportar muy grandes ventajas de uso a la población valenciana.

Fechado en Madrid, el 28 de diciembre de 1844, el Ministerio de Instrucción Pública se dirige al presidente de la Comisión de Monumentos de Madrid, concretamente al subsecretario Juan José Mentria [?] diciéndole que «a fin de evacuar por este Ministerio el informe que sobre la conservación del monasterio de San Miguel de los Reyes se ha pedido de Real Orden por el Ministerio de Hacienda, es conveniente que esa Comisión diga lo que se le ofrezca acerca de ese particularm.

De la Comisión de Monumentos hay un oficio del 13 de mayo de 1844 a propósito de los edificios de aquella ciudad [Valencia] «...el monasterio de San Miguel de los Reyes, fundado por los Duques de Calabria extramuros encierra un cúmulo de riquezas artísticas y recuerdos históricos contándose entre aquellos los sepulcros de los fundadores. La Academia ha solicitado varias veces con notable empeño la conservación de este edificio y el jefe político secundando este deseo propuso se destine a fábrica de tabacos, alegando importantes razones de conveniencia» (A.A.S.F. Leg. 53-3/2).

En nombre del gobierno político de Valencia, Francisco Carbonell escribe al Ministro de la Gobernación con fecha 14 de agosto de 1844, a propósito de las riquezas del monasterio: «Los libros, los manuscritos y los códices que, según la circular, deben destinarse a la creación de una Biblioteca Provincial están recogidos años ha y magníficamente colocados en la Biblioteca de la Universidad. Allí se encuentran todos los libros de algún mérito que pertenecieron al clero regular y los preciosos manuscritos del convento de San Miguel de los Reyes.

Las pinturas procedentes del mismo origen que no ha destruído o extraviado la revolución, están colocadas en el ex convento de carmelitas calzados: Juan de Juanes, Ribaltas, Espinosa, Borrás, de Salvador y de otros pintores célebres de esta escuela. Casi nada hay de escuela sevillana y muy poco de escuelas extranjeras.

En esculturas las hay de poco mérito excepto del célebre escultor Vergara" (A.A.S.F. 53-3/2).

En el mismo legajo, con fecha 17 de febrero de 1844, hay una noticia de los carmelitas pidiendo protección para sus depósitos, y con fecha 20 de julio de 1845, se habla de la necesidad de hacer un catálogo razonado de la pintura del museo en un informe al ministerio. Al año siguiente, 1846, el 24 de junio, la Comisión de Monumentos se dirige a Gobernación sobre la dificultad de hacer el catálogo de pintura y escultura del museo "por las retribuciones». No obstante hay una noticia del 12 de octubre de 1846 en la que el Gobierno Político de Valencia comunica al Ministerio de Gobernación que el catálogo se halla ya a la mitad y lo está haciendo don Miguel Parra (A.A.S.F. Leg. 53-3/2).

El gobierno eclesiástico de la provincia de Valencia da una nota - sin fecha- de los edificios suprimidos, cuyas iglesias deben conservarse por su mérito artístico o por la utilidad que presentan: «San Miguel de los Reyes extramuros, situado en las cercanías de la capital, es uno de los

\footnotetext{
39 A.H.N., Códice 508.

40 Los legajos del Archivo de la Academia de San Fernando van reseñados en el texto. Otra bibliografía citada: Orellana: Biografía pictórica valentina, Valencia, 1967; F. M. Ortiz de Taranco: Catálogo Monumental de la ciudad de Valencia, Valencia, 1983.
} 
grandes monumentos artísticos de recuerdos históricos y glorias nacionales; es fundación de los Duques de Calabria, cuyos sepulcros magníficos adornados con mosaicos allí existen. La Academia ha solicitado su conservación y bien lo merece un edificio que tanto honra al país» (A.A.S.F. Leg. 53-3/2).

En otro informe del mismo legajo, fechado el 28 de abril de 1849 y firmado por el director general Antonio Gil de Zárate, el Ministerio de Hacienda dice al de Comercio e Instrucción que ha dado cuenta a la Reina de las reclamaciones de la Academia de Nobles Artes [San Carlos] y Ayuntamiento de la ciudad de Valencia de que se halla a la venta el monasterio de San Miguel de los Reyes, extramuros, por ser digno de conservarse en razón de las bellezas artísticas que encierra.

Existen en el mismo legajo de la Academia otros papeles sin fecha referentes al tema. Así, la Academia de San Carlos de Valencia, se dirige al Gobierno Político de la provincia en los siguientes términos: «Más de una vez esta Academia de Nobles Artes, llevada del celo que la distingue por la conservación de las mismas, ha respondido a la voz del gobierno procurando informarle acerca de las preciosidades artísticas contenidas en los muchos y suntuosos edificios que ostentaba con gloria esta provincia abrigando esta corporación una segura esperanza de su conservación al observar el interés que se mostraba por adquirir estos conocimientos. Viendo defraudadas sus fundadas esperanzas y levantada la mano atroz de la revolución, o por mejor decir armada del pico y la palanca la asquerosa mano de ambiciosos especuladores disfrazados con carácter de patriotismo e ilustración, ha levantado voluntariamente el grito que excitara al sentimiento natural al ver destruise por un mezquino interés privado, altos recuerdos de ilustración nacional, monumentos eternos de cultura y civilización; así lo ha apuntado al gobierno en varias ocasiones para que la nota común de barbarie en que los enemigos de nuestras glorias han querido envolvernos, exceptuara este pequeño recinto del templo de las artes de Valencia donde sus individuos se retiraron a llorar la desolación universal, esperando que allí les alcanzara también el fatal golpe de la destitución; no obstante esta cordial manifestación de sus sentimientos reconocida por el gobierno de S.M. en su Real Orden de 2 de abril último no puede menos la Academia de responder a la invitación que nuevamente la hace el gobierno para darle una razón circunstanciada de los templos y edificios que pertenecieron a las comunidades religiosas y corporaciones suprimidas en las cuales existan algunas bellezas artísticas o que encierren en su recinto objetos que por algún título sean dignos de respeto y conservación: Monasterio de San Miguel de los Reyes: Ninguno sin duda ofrece en las cercanías de Valencia recuerdos históricos y artísticos más gloriosos que el que vamos a tratar, y sobre el cual la Academia ha llamado especialmente la atención de la superioridad para que respeten sus bellezas. La Academia siguiendo su sistema y las sabias huellas que sobre el particular le trazaron la ilustrada Sociedad Económica de Amigos del País en el resumen histórico que de este edificio dirigió al Gobierno y tiene consignado en su Boletín Oficial $\mathrm{V}^{\circ} \mathrm{LI}$ [?] correspondiente al mes de abril de 1840, pudiera hacer una reseña histórica de las altas glorias que hacen a este edificio perteneciente a la historia nacional, mas el temor de hacer prolija y tal vez pesada la reseña de que se trata, la obliga a ceñirse estrictamente a su parte artística. Este monasterio ostenta en sus muros construídos todos de sillería en sus altos torreones y cimborrio que se distinguen a lo lejos, una suntuosidad y magnificencia propia de las Reales personas que lo levantaron. La fachada principal de su iglesia con sus dos torres de campanas manifiestan la grandeza de alma del artífice que la inventó y la felicidad con que la ejecutó; su altura consta de unos noventa pies distribuída en seis cuerpos de seis columnas, de los órdenes dórico, jónico y corintio, adornado de estatuas oportunamente colocadas, cuya obra forma su conjunto que inspira admiración y respeto. A la derecha de la fachada está la portería por la que se penetra al claustro antiguo, que sin dudar es la parte más suntuosa del edificio por su construcción de sillería y proporciones de su grave arquitectura, que sorpren- 
de y embelesa: su figura es cuadrada en sus lados de ciento sesenta pies con nueve arcos en cada piso; se compone de dos cuerpos en su todo parecidos al claustro llamado de los Evangelistas en el Escorial, el inferior dórico y jónico el superior, uno y otro con colunas amarradas sobre pedestales coronados por una balaustrada que corre sobre el cornisamento del segundo en el ángulo de la derecha de su entrada y en el centro del mismo se halla la escalera principal atrevida y espaciosa, la cual se divide en dos tramos con bóvedas de cantería de extraordinario mérito que conducen al claustro alto, pero todavía se [?] por mejor otra escalera que es de un solo tramo que por su mesilla de montea sumamente rebajada, merece estuviese como modelo de buena construcción. Junto a la escalera principal se encuentra una capilla notable por su graciosa bóveda; siguiendo el mismo lienzo se llega a la hermosa pieza del refectorio que con algunas otras oficinas ocupa el lado del mediodía, avanzando en los extremos por el esterior dos torreones de considerable altura y solidez que dividen también los pisos con bóvedas de ladrillo muy bien dispuestas; dando la buelta al lado opuesto se halla una de las puertas de la iglesia que dan a su crucero. Esta aunque de una nave es grandiosa y bien proporcionada, su forma es de cruz latina con cinco capillas en cada lado que tienen tribunas encima y partes adornadas de pilastras, el coro está a la entrada principal sostenido por arcos extraordinariamente rebajados, resaltando sobre todo en este templo el cimborrio que elegantemente se eleva de figura igual al de El Escorial, enriquecido con abundantes y exquisitos mármoles de este Reyno; de esta materia es el magnífíco graderío y balaustrada del presbiterio en cuyos lados se elevan los nichos que profusamente guarnecidos ocupaban las figuras de los Illtres. Fundadores los Duques de Calabria en correspondencia de sus sepulcros que subsisten en el Panteón construído bajo la enorme masa del altar mayor, obra admirable por el prolijo trabajo de los mosaicos que lo adornan. Este edificio cuya conservación ha solicitado con tanto empeño la Academia, honra a nuestro pais y debe conservarse a todo trance» (A.A.S.F. 53-3/2).

Existe también en este mismo legajo un informe de la Real Academia de la historia sobre los monumentos históricos de la provincia de Valencia y, como es lógico, se refiere en primer lugar a San Miguel de los Reyes, repitiendo casi exactamente la descripción que acabamos de transcribir de la Academia de San Carlos.

El monasterio ha sido restaurado en la actualidad y está a la espera de darle un destino oficial. 